\author{
Ю.Б. Орлицкий \\ Российский государственный гуманитарный университет \\ (Россия, Москва) \\ ju_b_orlitski@mail.ru
}

\title{
НЕОЛОГИЯ И РИФМА (ФУТУРИСТЫ, СОВЕТСКИЕ ПОЭТЫ, САПГИР, СОВРЕМЕННЫЕ АВТОРЫ)*
}

В статье на материале русской поэзии XX века (футуристы, неоавангардисты) рассматриваются особенности использования неологизмов разного типа и функционально близких к ним слов в позиции рифмы - компонента стиховой структуры, постоянно нуждающегося в обновлении. Начало систематическому применению неологизмов и их имитаций (например, «детских» слов) в рифме восходит к творчеству русских футуристов: Хлебникову, Маяковскому, Крученых, Каменскому. Затем, в советский период, русские поэты для той же цели часто помещают в рифменную позицию разного рода экзотическую лексику: имена, географические и иные названия, специальную терминологию. Наконец, в новейшей экспериментальной поэзии в качестве рифмующихся слов вновь начинают использоваться неологизмы или функционально близкие им фрагменты слов. Особое внимание в статье уделено словотворческой практике Генриха Сапгира и его поэтике полуслова, активно работающей и на создание новых рифменных созвучий.

Ключевые слова: поэтическая неология, стиховой перенос, поэтика полуслова, рифма, футуризм, Генрих Сапгир.

Использование неологизмов разного типа и функционально близких к ним слов в новейшей поэзии открывает новые возможности не только для порождения смыслов, но и для развития самого стиха. В этом смысле интересно попристальнее присмотреться к творчеству авторов XX века, впервые активно и осознанно использовавших этот неисчерпаемый творческий ресурс - прежде всего, Велимира Хлебникова и его соратников, русских футуристов. Поскольку неология

* Работа выполнена в рамках международного научного проекта «Lyrik in Transition: Poetische Formen des Umgangs mit Grenzen der Gattung, Sprache, Kultur und Gesellschaft zwischen Europa, Asien und Amerika» (Universität Trier) 
Хлебникова уже становилась объектом серьезного рассмотрения [Григорьев 1986; Перцова 1995, 2012] обратимся к опыту других будетлян.

Наиболее очевидно обогащение стиха неологизмами разной природы происходит в рифме, которая является наиболее «стареющим» механизмом стиховой культуры. Как раз на рубеже XIX и XX происходит очередной кризис русской рифмы [Гаспаров 2000: 249-260 и др.], выход из которого - прежде всего, за счет использования новых рифм и принципов рифмовки - интуитивно ищут, с одной стороны, поэты-сатирики и юмористы (например, из круга «Сатирикона»), а с другой - именно футуристы: Маяковский, Хлебников и другие. Например, «горбил - был», «златолобо - зашло бы» Маяковского, «поюнней воюнней», «красавец - небесавец», «лучбища - всеучбища» Хлебникова, «левянку - полянку — милянку» Каменского, «сустень — грустную» (Крученых) и т. д.

Один из наиболее радикальных словотворцев и теоретиков обновления русского стиха Алексей Крученых писал в 1919 г. (неологизмы в рифменной позиции здесь и далее выделены курсивом):

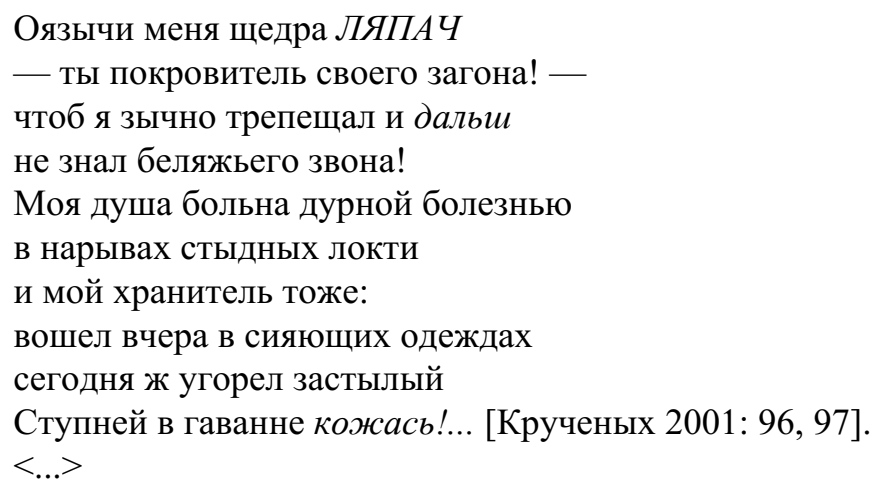

Стихотворение написано гетероморфным стихом на ямбической основе [Орлицкий, Андреева 2008; Орлицкий 2018]; четыре строки из десяти - холостые. Из пяти неологизмов разного типа, использованных в стихотворении (в примере они выделены курсивом), три попадают в рифменную позицию, причем два (ЛЯПАЧ и дальш) зарифмованы между собой.

Василий Каменский тоже является автором множества окказиональных словообразований; например, в стихотворении «Акафист», большая часть которого написана свободным стихом, первые строки каждого из девяти катренов зарифмованы между собой (приведем только эти строки):
О поэтическая печаль
О поэтическая венчаль
О поэтическая молчаль
О поэтическая звучаль 

О поэтическая встречаль
О поэтическая ярчаль
О поэтическая раскачаль
О поэтическая началь
О поэтическая скончаль [Каменский 1918: 45-46].

Другое стихотворение Каменского - «Колыбайка» - состоит в основном из неологизмов, имитирующих «детский» язык; большинство из них рифмуется между собой; для экономии места приведем его в прозаической записи:

Линьничка / Минничка / Летка / Хорошечка / Славничка / Байничка / Спинничка /спи-спи-спи.

Кусареньки / Мареньки / Дареньки / Жареньки / Ббусы / Ракушки / Камушки / спи.

Цинить-тюрлью / Цинить-тюрлью / Улетелечки / Птички / Песенки / Лесенки / Палькай / Водички / и спи-спи-спи.

Мушки у / Ямушки / Лягушки / Квакушки / Барашки с / Рожками / Кружочки / Снежочки / спи-спи.

Малякаля / Бакаля / Куколки / Мячики / Крылышки / ш-ш-ш-ш / ушки-игрушки / спатеньки / слатеньки / спи летка / солничка / спи-ау-ау-ау-ау. [Каменский 1917: 68-71].

Немало примеров использования неологизмов, в том числе и замаскированных под диалектные слова, дает и Сергей Есенин; в этом смысле особенно интересна его «Песнь о Евпатии Коловрате» (1912), более половины аномальных слов в которой находятся в концах строк, то есть в потенциально рифменной позиции:

За поёмами Улыбыша
Кружат облачные вентери.
Закурилася ковыльница
Подкопытною танагою.
Ой, не зымь лузга-заманница
Запоршила переточины,--
Подымались злы татаровья
На зарайскую сторонушку.
Не ждала Рязань, не чуяла
А и той разбойной допоти,
Под фатой варяжьей засынькой
Коротала ночку темную [Есенин 1997: 174].

В советское время поэты, как известно, вынужденно отказались от неологии; в ее функции в рифменной позиции использовалась экзотическая лексика: имена, географические названия, научные термины. Особенно активно это происходит в стихотворениях, написанных во время поездок поэтов в экзотические места. Так, в 1956 г. Белла Ахмадулина пишет стихотворение «Грузинских женщин имена», 
в котором восхищается ими; в стихах названы пять женских имен, три из которых помещены в рифменную позицию: «Ламара — ломала», «Медеи — мелели» и «олеандры - Ариадны» [Ахмадулина 1979: 11].

Михаил Матусовский в 1968 г. публикует книгу «Тень человека» [Матусовский 1968], посвященную хиросимской трагедии; название этого японского города в разных падежах 25 раз использовано в рифменной позиции и ни разу в середине или начале строки, еще два раза оно встречается в нерифмованных стихах и один раз - в прозаической вставке. Кроме того, дважды ключевое слово книги попадает в заглавия стихотворений. Таким образом, практически всегда название «Хиросима» используется советским поэтом для создания оригинальной рифмы.

Это только два примера, а практически каждый официальный советский поэт, путешествуя по миру, непременно привозил с собой новые стихи и новые рифмы. Вспомним хотя бы знаменитые строки Игоря Кобзева:

Кого-то терзает зависть

К едущим за границу:

Счастиливый какой, мерзавец, Увидит Марсель и Ниццу.

Среди авторов неподцензурной литературы чаще всего использует неологизмы в позиции рифмы Генрих Сапгир [Орлицкий 2016]. Именно этот прием оказывается в центре внимания в его книге 1984-1987 гг. «Терцихи Генриха Буфарева». Вот, например, начало стихотворения «Киоск курорга»:

Киоск курорга: старый добрый пластик

На выбор - сумки, рюмки, жустик, хрястик

— Вам нужен блист? Здесь есть похожий блистик

Народ глядит. Внутри ряды резин

и никчемушек полный гамазин

Набычил глаз небритый баргузин [Сапгир 2008: 267].

Второй важный источник обновления рифмы - стиховой перенос, прерывающий стиховой ряд на границе слова; на это явление в свое время обратил внимание Д. Кузьмин (например, «в разрезе - И презе- (нтовать)» (Антон Колобянин); «на не- (деле) — / в волне» (Алексей Пурин); «разговор / в громкого- (воритель)» (В Ефимов) [Кузьмин 2003].

Этот прием Сапгир использует в своих так называемых «полусловах» (термин Л. Зубовой) [Зубова 2000: 194] — можно сказать, фрагментарной, частичной, предполагающей читательскую расшифровку, но не восстановление исходной формы слов. Такие «частичные» слова обычно появляются на границах стихотворных слов и образуют необычные рифмы; ср. в том же «Киоске курорга»: 
Тигрессы, вепри, бракодабра, на-

рисованы на майках и штана-

Хватают все. Такие времена [Сапгир 2008: 267].

Если в конце первой строки перед нами пример рифмы на переносе, то во втором перед нами усеченное (полу-) слово - особого рода окказиональный неологизм. Вот начало стихотворения «Поиски щенка» из книги 1988 г. «Дети в саду», целиком построенной на «поэтике полуслова»:

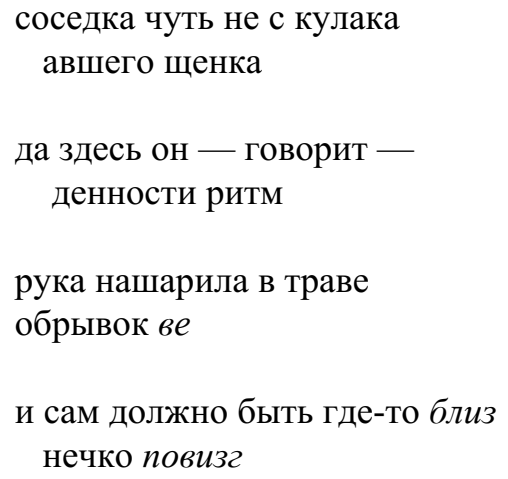

а ты все ищешь вообще и все скулишь как щ̧е [Сапгир 2008: 306].

В открывающем эту книгу стихотворении «Сад» усечения слов используются для рифмообразования регулярно:

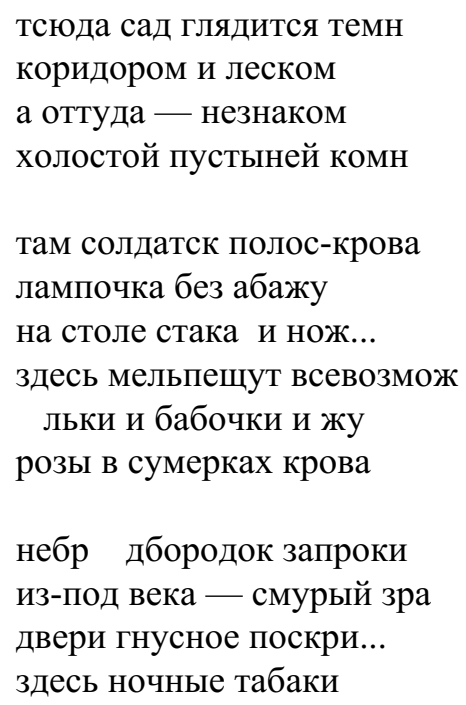




\author{
пахнут - сердце замира \\ а гвоздики - хоть умри \\ где бы ни был - зде и ве \\ мне сквози двойная те- \\ кровь и рвота на газе \\ мяч потерянный в траве [Сапгир 2008: 306].
}

Все названные приемы находят продолжение как в творчестве новейших поэтов-экспериментаторов - Ры Никоновой, С. Сигея, К. Кедрова, С. Бирюкова, Е. Харитонова, - так и в отдельных произведениях авторов-традиционалистов, позволяющих таким образом оживлять рифменную картину своего стиха.

\title{
Литература
}

Ахмадулина Б. А. Грузинских женщин имена // Ахмадулина Б. А. Сны о Грузии. Тбилиси: Мерани, 1979. С. 11.

Гаспаров М. Л. Очерк истории русского стиха. Метрика. Ритмика. Рифма. Строфика. Изд. 2-е (доп.). М.: «Фортуна Лимитед», 2000. 352 с.

Григорьев В.П. Словотворчество и смежные проблемы языка поэта. М.: Наука, 1986. 253 c.

Есенин С. А. Песнь о Евпатии Коловрате // Есенин С. Полное собрание сочинений. В 7-ми томах, девяти книгах. Том 2. Стихотворения. Маленькие поэмы. М. Наука-Голос. 1997. С. 174-180.

Зубова Л. В. Современная русская поэзия в контексте истории языка. М.: НЛО, 2000. 432 c.

Каменский В. В. Акафист // Каменский В. В. Звучаль Веснеянки. М.: Китоврас, 1918. С. 45-46.

Каменский В.В. Колобайка // Каменский В. В. Девушки босиком: Стихи. Тифлис: тип. «Прогресс», 1917. С. 68-71.

Крученых А.Е. Оязычи меня щедра ЛЯПАЧ; Моя душа больна дурной болезнью... // Крученых А.Е. Стихотворения. Поэмы. Романы. Опера. Сост., подг. текста, вст. ст. и примеч. С.Р. Красицкого. СПб. Академический проект. 2001. С. 96, 97.

Кузьлин Д. В. План работ по исследованию внутрисловного переноса // НЛО. 2003. № 59. С. 392-409.

Матусовский М.Л. Тень человека. Книга стихотворений о Хиросиме, о ее борьбе и ее страданиях, о ее людях и ее камнях. М.: Сов. писатель, Москва, 1968. 92 с.

Орлицкий Ю.Б., Андреева А.Н. Гетероморфный стих в современной русской поэзии // Славянский стих. VIII. Материалы междун. научн. конф. М.: Языки слав. культур, 2008. С. 365-389.

Орлицкий Ю. Б. Особенности стихосложения Алексея Крученых (2018, в печати).

Орлицкий Ю. Б. Словотворческая практика Генриха Сапгира // Труды Института русского языка им. В.В. Виноградова. Т. VII. Материалы международной научной 
конференции «Первые Григорьевские чтения: Языковое творчество vs. креативность: эстетический, эвристический и прагматический аспекты» (12-14 марта 2015 г.). М., 2016. С. 321-337.

Перияова Н.Н. Словарь неологизмов Велимира Хлебникова. Wien - Moskau (Wiener Slawistischer Almanach; Sonderband 40), 1995. 540 c.

Перизова Н. Н. Словотворчество Велимира Хлебникова / Н. Н. Перцова; предисл. Роналда Вроона. 2-е изд. М. : Изд-во Московского университета, 2012. 188 с.

Сапгир Г. В. Складень. М.: Время, 2008. 928 с.

\section{Y. B. Orlitsky}

Russian State University for the Humanities

(Russia, Moscow)

ju_b_orlitski@mail.ru

\section{NEOLOGY AND RHYME (FUTURISTS, SOVIET POETS, SAPGIR, MODERN AUTHORS)}

The article on the material of the XX century Russian poetry (futurists, neoavantgarde) describes peculiarities of using neologisms of different types and functionally related words in position of rhyme - a component of the verse structure constantly in need of renewal. The beginning of systematic use of neologisms and their imitations (for example, «children's» words) in rhyme dates back to the works of Russian futurists: Khlebnikov, Mayakovsky, Kruchenykh, Kamensky. Then, in the Soviet period, Russian poets for the same purpose often put in the rhyming position all sorts of exotic vocabulary: names, geographical and other names, special terminology. Finally, in recent experimental poetry, neologisms or fragments of words functionally close to them begin to be used as rhyming words again. Special attention is paid to neological practice of Genrikh Sapgir.

Key words: neology in poetry, enjambement, halfword poetics, rhyme, futurism, Genrikh Sapgir.

\section{References}

Akhmadulina B.A. [Georgian women names]. Akhmadulina B.A. Sny o Gruzii. Tbilisi: Merani Publ., 1979, p. 11. (In Russ.)

Gasparov M. L. Ocherk istorii russkogo stikha. Metrika. Ritmika. Rifma. Strofika [Essay on the history of Russian verse. Metrics. Rhythm. Rhyme. Stanza]. $2^{\text {nd }}$ ed. (enlarged). Moscow, Fortuna Limited Publ., 2000. 352 p.

Grigor'ev V.P. Slovotvorchestvo i smezhnye problemy yazyka poeta [Word creation and related problems of the poet's language]. Moscow, Nauka Publ., 1986. 253 p. 
Esenin S. A. [Song of Evpatii the Kolovrat]. Esenin S. Polnoe sobranie sochinenii. V 7-mi tomakh, devyati knigakh. Tom 2. Stikhotvoreniya. Malen'kie poemy [Complete works. In 7 vols., 9 books. Vol. 2]. Moscow, Nauka-Golos Publ., 1997, pp. 174-180. (In Russ.)

Zubova L.V. Sovremennaya russkaya poeziya $v$ kontekste istorii yazyka [Modern Russian poetry in the context of the history of language]. Moscow, NLO Publ., 2000. $432 \mathrm{p}$.

Kamenskii V. V. [Akathist]. Kamenskii V.V.Zvuchal' vesneyanki. Moscow, Kitovras, 1918, pp. 45-46. (In Russ.)

Kamenskii V. V. [Kolobaika]. Kamenskii V. V. Devushki bosikom: Stikhi [Barefooted girls. Poems]. Tiflis, Progress Printing House, 1917, pp. 68-71. (In Russ.)

Kruchenykh A.E. [Oyazychi menya shchedra LYaPACh; My soul has a bad disease...]. Kruchenykh A.E. Stikhotvoreniya. Poemy. Romany. Opera [Poems. Novels. Opera]. S. R. Krasitsky (comp., ed., preface, comments). St. Petersburg, Akademicheskii Proekt, 2001, pp. 96, 97. (In Russ.)

Kuz'min D. V. [Work plan for the study of intra-word enjambement]. NLO, 2003, no. 59, pp. 392-409. (In Russ.)

Matusovskii M.L. Ten' cheloveka. Kniga stikhotvorenii o Khirosime, o ee bor'be i ee stradaniyakh, o ee lyudyakh i ee kamnyakh [The shadow of man. A book of poems about Hiroshima, her struggle and her suffering, her people and her stones]. Moscow, Sovetskii Pisatel' Publ., 1968. 92 p.

Orlitskii Yu. B., Andreeva A.N. [Heteromorphic verse in modern Russian poetry]. Slavyanskii stikh. VIII. Materialy mezhdun. nauchn. konf. Moscow, Yazyki slavyanskikh Kul'tur Publ., 2008, pp. 365-389. (In Russ.)

Orlitskii Yu. B. Osobennosti stikhoslozheniya Alekseya Kruchenykh [The features of the poetry of Alexei Kruchenykh]. 2018, in print.

Orlitskii Yu. B. [The word creative practice of Genrikh Sapgir]. Trudy Instituta russkogo yazyka im. V.V. Vinogradova. Vol. VII. Materialy mezhdunarodnoi nauchnoi konferentsii «Pervye Grigor'evskie chteniya: Yazykovoe tvorchestvo vs. kreativnost': esteticheskii, evristicheskii i pragmaticheskii aspekty» (12-14 marta 2015 g.). Moscow, 2016, pp. 321-337. (In Russ.)

Pertsova N. N. Slovar' neologizmov Velimira Khlebnikova. [The dictionary of Velimir Khlebnikov's neologisms]. Wien-Moskau (Wiener Slawistischer Almanach; Sonderband 40), 1995. $540 \mathrm{p}$.

Pertsova N. N. Slovotvorchestvo Velimira Khlebnikova. [Velimir Khlebnikov's word creation]. Moscow, Moscow State Univ. Publ., 2003. 176 p.

Sapgir G. V. Skladen' [Triptych]. Moscow, Vremya Publ., 2008. 927 p. 